\title{
Enhanced toughness and stable crack propagation in a novel tungsten fibre-reinforced tungsten composite produced by chemical vapour infiltration
}

\author{
J Riesch $^{1}$, T Höschen ${ }^{1}$, Ch Linsmeier ${ }^{2}$, S Wurster ${ }^{3}$ and J-H You ${ }^{1, *}$ \\ ${ }^{1}$ Max-Planck-Institut für Plasmaphysik, EURATOM Association, 85748 Garching, Germany \\ ${ }^{2}$ Forschungszentrum Jülich GmbH, Institut für Energie und Klimaforschung - Plasmaphysik, EURATOM \\ Association, 52425 Jülich, Germany \\ ${ }^{3}$ Erich Schmid Institute of Materials Science of the Austrian Academy of Sciences, EURATOM Association, \\ 8700 Leoben, Austria \\ *Corresponding author: jeong-ha.you@ipp.mpg.de
}

\begin{abstract}
Tungsten is a promising candidate for the plasma-facing components of a future fusion reactor, but its use is strongly restricted by its inherent brittleness. An innovative concept to overcome this problem is tungsten fibre-reinforced tungsten composite. In this article we present the first mechanical test of such a composite material using a sample containing multiple fibres. The in-situ fracture experiment was performed in a scanning electron microscope for close observation of the propagating crack. Stable crack propagation accompanied with rising load bearing capacity is observed. The fracture toughness is estimated using the test results and the surface observation.
\end{abstract}

\section{Introduction}

Tungsten is a promising candidate for the plasma-facing components of a future fusion reactor due to its unique combination of properties such as the very high melting point or the good thermal conductivity [1, 2]. However, tungsten features a ductile-to-brittle transition (DBT), which is depending on the type of experiment and fabrication route - at several hundred degrees centigrade. The occurrence of a DBT means that below a certain temperature tungsten behaves brittle. In addition, tungsten is heavily embrittled both by recrystallization and neutrons from the fusion reaction [1-3]. Numerous efforts are undertaken to overcome these problems. Detailed reviews on the progress in making tungsten applicable for fusion can be found elsewhere [4, 5].

An innovative solution using a composite concept has been developed at the Max-Planck-Institute für Plasmaphysik (IPP) in the past years. It consist of a tungsten matrix, produced by a chemical vapour reaction, which is reinforced by drawn tungsten wires coated with an engineered interface [6-10]. The new material is a tungsten fibre-reinforced tungsten composite $\left(\mathrm{W}_{\mathrm{f}} / \mathrm{W}\right)$. In this material, the toughness is enhanced by extrinsic mechanisms of energy dissipation rather than by conventional ductilization mechanisms like alloying or thermo-mechanical treatment.

In brittle materials such as bulk tungsten there is no possibility of stress redistribution and this leads to a scattering in strength and flaw sensitivity [11], and therefore a lack of reliability. Extrinsic toughening is the only method which allows the toughening of brittle materials [12,13] and is widely used in ceramic fibre-reinforced ceramics $[14,15]$. The underlying mechanisms allow the dissipation of energy and thus relaxation of stress peaks. Typical mechanisms are crack deflection at interfaces, crack tip shielding by fibre bridging, or energy dissipation by fibre pull-out [14, 16-19]. The most effective mechanisms are the pull-out and the ductile deformation of the reinforcements [20]. As most of the toughening mechanisms do not require material plasticity, tungsten is toughened below the DBT temperature (DBTT) and above the recrystallization temperature, as well as during operation in a neutron flux.

For miniaturized $\mathrm{W}_{\mathrm{f}} / \mathrm{W}$ composites samples the strong contribution to the toughness by ductile fibre deformation has been shown [9]. These miniaturized samples are single fibre composites which contain only one single fibre within a tungsten matrix the crack stopping, bridging, deflection and meandering was shown in bending tests for as-produced and embrittled samples [10]. 
In this contribution, we present the first mechanical test of a multi-fibre $\mathrm{W}_{\mathrm{f}} / \mathrm{W}$ composite. A careful sample preparation and the surface observation by a scanning electron microscope (SEM) during the bending experiment allow to observe the interaction between cracks and microstructure. We present the details of the manufacturing route, the testing method and the results of the surface observation together with an estimation of the toughness.

\section{Fabrication of a multi-fibre $W_{f} / W$ composite by chemical vapour infiltration}

Classical composite production routes like liquid infiltration or diffusion bonding (details in [14]) are not readily applicable for $\mathrm{W}_{\mathrm{f}} / \mathrm{W}$ due to the very high melting point and high temperature strength of tungsten and the fact that fibre and matrix have similar properties. Therefore, a chemical deposition route is used for the production of $\mathrm{W}_{\mathrm{f}} / \mathrm{W}$. A fibrous preform consisting of tungsten wires with a diameter of $150 \mu \mathrm{m}$ is infiltrated with gaseous $\mathrm{WF}_{6}$ and $\mathrm{H}_{2}$. In a surface reaction the $\mathrm{WF}_{6}$ is reduced by the $\mathrm{H}_{2}$ to form the tungsten matrix. This allows low processing temperatures $\left(<600^{\circ} \mathrm{C}\right)$ and a force-less fabrication, and thus the preservation of the interface integrity.

A general problem of a chemical infiltration technique is the remaining porosity in the produced bulk material. This can be influenced by varying the fibre arrangement, gas flow and temperature distribution during the chemical deposition. The first attempts for the production of bulk $\mathrm{W}_{\mathrm{f}} / \mathrm{W}$ composites by chemical vapour infiltration used a gas flow perpendicular to the fibre axis and a variable temperature distribution. With this technique the fabrication of composite material up to a density of $80 \%$ was possible [21]. Nevertheless, the remaining pores are concentrated between the fibres and only a poor compactness is achieved by that procedure. A gas flow longitudinal to the fibres allows the fabrication of compact specimens, but is technically more demanding.

(a) CVI step 1

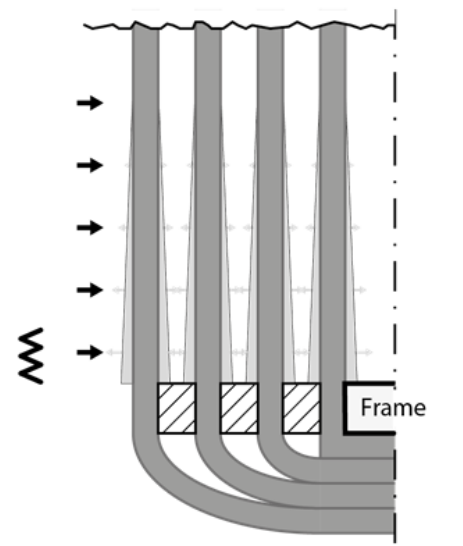

(b) CVI step 2

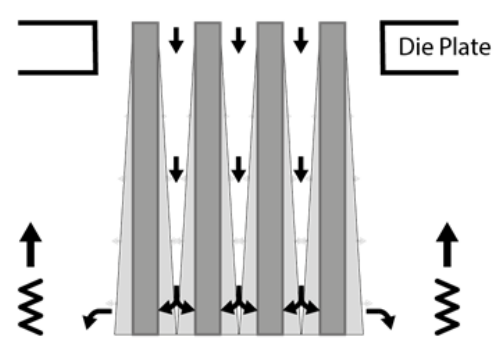

w-Fibre spacer Gas flow $\mathrm{WF}_{6}+\mathrm{H}_{2}$

Figure 1: Gas transport and deposition profiles of a dual step chemical vapour infiltration process for $W_{f} / W$. In (a) the first CVI step with perpendicular gas flow on a winded preform (only half of the frame is shown) is shown. In (b) the second CVI step with longitudinal gas flow on a freestanding preform is shown.

To allow longitudinal gas flow, the fibre preform has to be accessible along the fibre axis. The previously used winding technique [21] allows the production of well-ordered fibre arrangements, but blocks the access along the fibres (see figure 1.a). By using a dual step CVI process combining a perpendicular and a longitudinal gas flow, dense $\mathrm{W}_{\mathrm{f}} / \mathrm{W}$ is produced. A first infiltration step with a gas flow perpendicular to the fibres in combination with a thermal gradient produces a triangular deposition profile with touching fibres at one end (hotter area) and loose fibres at the other end (see figure 1.a). This sample is then cut free and due to the touching region, a freestanding sample is 
achieved. The sample is mounted into the CVI reactor for a second time whereas the free fibres are located within a die plate (see figure 1.b). The reaction gas flows along the fibres in a longitudinal direction. By applying a thermal gradient, the fibre preform starts to consolidate from the hotter region. The sample is fully consolidated by moving the heater along the preform.

A preform consisting of 9 layers with 10 fibres each is used for the here shown investigations. It is 100 $\mathrm{mm}$ long and $2 \mathrm{~mm}$ thick. This preform is then treated under perpendicular gas flow for $12 \mathrm{~h}$. The gas flow is $62 \mathrm{sccm}^{1} \mathrm{WF}_{6}$ and $250 \mathrm{sccm} \mathrm{H}_{2}$. A local heat source at the lower end of the preform is used to create a temperature profile with $563 \mathrm{~K}$ at the upper end and $741 \mathrm{~K}$ at the lower end, resulting in a temperature gradient of $2.1 \mathrm{~K} / \mathrm{mm}$. The produced sample is then cut free to get a second preform with a length of $25 \mathrm{~mm}$. This preform is infiltrated in longitudinal direction for $34 \mathrm{~h}$ with a gas flow of 40 sccm $\mathrm{WF}_{6}$ and $150 \mathrm{sccm} \mathrm{H}_{2}$. Again a local heat source is used to produce a thermal gradient. The position of the heat source was kept constant and close to the lower end of the preform for $10 \mathrm{~h}$, leading to a temperature of $635 \mathrm{~K}$ at the lower end and $582 \mathrm{~K}$ at the upper end and a resulting temperature gradient of $2.1 \mathrm{~K} / \mathrm{mm}$. The heat source was moved upwards by $4.5 \mathrm{~mm} / \mathrm{h}$ during the remaining infiltration time.

A dense sample is produced by this fabrication procedure. Cross-sections of the top and the bottom parts show a porosity of less than $5 \%$. The porosity was determined as an average over several crosssections. figure 2 presents the cross-section at the bottom before and after the second infiltration. Very low porosity is present in longitudinal sections, but some larger pores exist. These pores are probably a consequence of the loose fibres at one end of the preform before the second CVI step. Some of these fibres may have touched in a way that closed pores are formed which cannot be infiltrated by the reaction gases. The final sample has a length of $25 \mathrm{~mm}$ and a cross section area of $3 \times 3 \mathrm{~mm}^{2}$, which was then used to produce the three-point bending (3PB) sample.

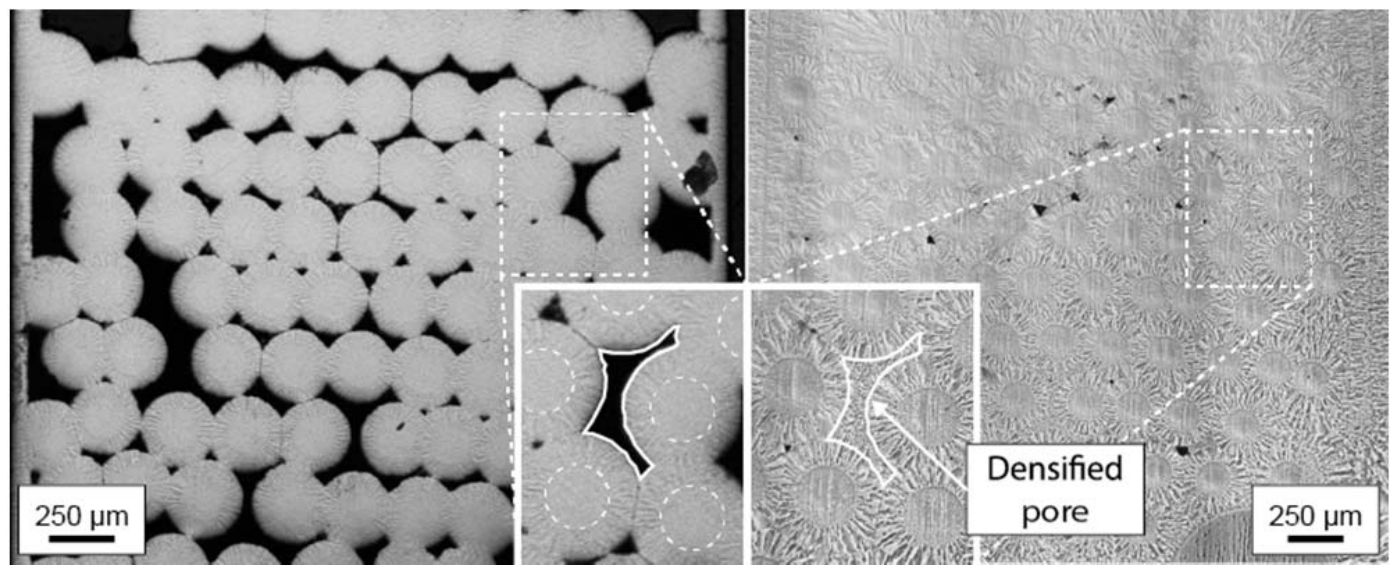

Figure 2: Cross-section at the bottom of the preform after the first CVI step with an infiltration perpendicular to the fibre axis (left) and after a second CVI step with a gas flow longitudinal to the fibre axis (right). The inserts show a pore which is filled during the second infiltration step. In the left detail picture dotted lines indicate the fibres.

\section{Bending test with in-situ surface observation by a scanning electron microscope}

Extrinsic toughening mechanisms only become active behind the crack tip [16]. Therefore, large samples are necessary to permit a proper crack development and to allow for a measurable effect on the toughening. To detect the crack initiation and its propagation, the sample surface is highly polished and carefully monitored during testing. A bending test according to ASTM E399 [22] is used to study the dynamic crack behaviour. The test is conducted within a scanning electron microscope (SEM, LEO Zeiss 1525), to allow high-resolution surface observations. The SEM is equipped with a Kammrath \& Weiss 3PB stage. This setup was already used for experiments on single-fibre $\mathrm{W}_{\mathrm{f}} / \mathrm{W}$

\footnotetext{
${ }^{1}$ standard cubic centimetre per minute
} 
samples [6]. It allows the observation of the interaction between the crack and the composite, i.e. fibre, matrix and interface, at its microstructural level.

\subsection{Sample preparation}

A careful surface preparation is required to allow the observation of the crack propagation. A combination of a mechanical (SiC grinding paper and diamond suspension) and a mechanicalchemical (Logitech SF1 "Syton") procedure is used (details in [23]). The sample is prepared such that the first layer of fibres is cut in half, which can be seen in figure 3. This allows the observation of the interaction of the crack with the first fibre layer in the surface. The sample contains $\mathrm{n}$ layers with $\mathrm{m}$ fibres each. To be able to distinguish the fibres, each fibre is identified by its layer and its position within the layer. To give an example, the second fibre in the first layer is labelled "fibre 1-2". The final 3PB sample has a length of $12.9 \mathrm{~mm}$, a height of $W=3.0 \mathrm{~mm}$ and a width of $B=2.2 \mathrm{~mm}$. The sample is notched to concentrate the stress at the notch tip and to create a well-defined crack initiation point. As a sharper crack lowers the load needed for crack initiation [24], a three-step notching procedure with decreasing notch radii is used. With a diamond wire saw a circular notch (radius 150 $\mu \mathrm{m}$ ) is formed. This notch is deepened using a razor blade polishing technique (details in [24]). The resulting notch radius is approximately $10 \mu \mathrm{m}$. Finally a focused ion beam (FIB) is used to produce two small adjoining pockets at the notch tip which act as dedicated crack initiation points [25]. The overall notch depth is $a=990 \mu \mathrm{m}$, which is approximately $30 \%$ of the sample height. figure 3 schematically shows the details of the sample and the notches.

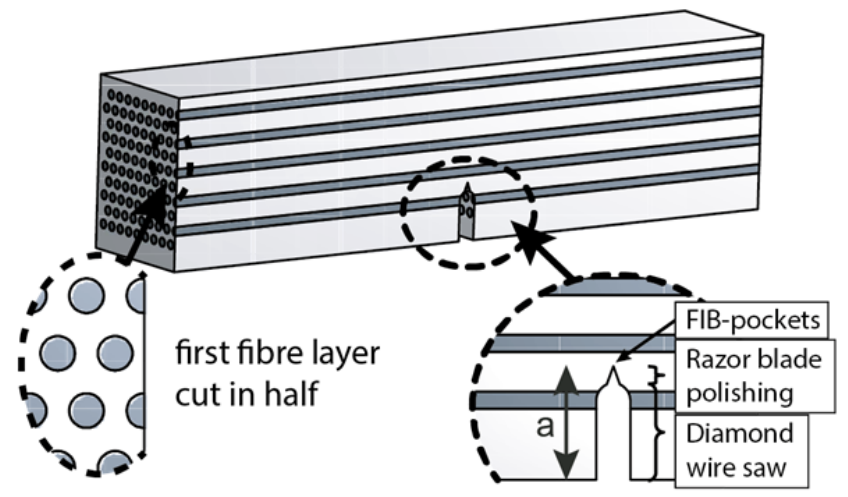

Figure 3: Schematic drawing of a multi-fibre $W_{f} / W$ bending sample with $n$ fibre layers with $m$ fibres each. The details show the first fibre layer which is cut in half, and the three-step notch with a depth of $a=990 \mu \mathrm{m}$.

\subsection{Bending test}

The bending unit is equipped with a sample holder (sample length 4-30 mm), a loading unit and measuring devices for load (max. $500 \mathrm{~N}$ ) and displacement. After mounting the sample onto the unit it is installed inside the SEM. The surface of the sample is perpendicular to the electron beam and orientated in a way that the load input is from top and bottom of the sample (see figure 4). The sample is loaded in a displacement-controlled manner while the crack tip (respectively the notch tip) is observed in a fast scanning mode to capture any changes at the crack tip immediately. To obtain high quality pictures or to scan the full sample an extended period of time is required. Therefore, the displacement is stopped when a defined load or displacement is reached or if a sudden change at the surface (e.g. crack propagation) is observed. After stopping, several high quality pictures are taken. The displacement is kept constant and due to relaxations a slight unloading of the sample may take place. The bending test is therefore conducted stepwise. 


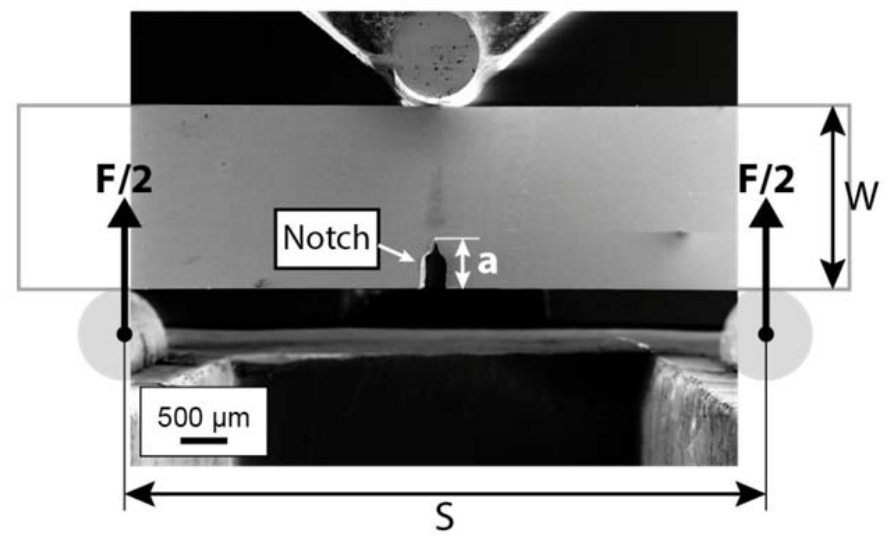

Figure 4: A Sample showing the typical 3PB geometry. Indicated are the dimensions $W=3.0 \mathrm{~mm}, a$ $=990 \mu \mathrm{m}, \mathrm{S}=10 \mathrm{~mm}$ and the corresponding load transfer points.

\section{Results}

The load-displacement curve of the bending test on the multi-fibre $\mathrm{W}_{\mathrm{f}} / \mathrm{W}$ sample is shown in figure 5 . After mechanical setting of the setup, the load increases linearly (part I). At a load of $127 \mathrm{~N}$, crack initiation in the matrix is observed at the surface (step 3 in figure 5). The crack initiation is accompanied by a load drop of $2 \mathrm{~N}$. With on-going loading, stable crack propagation is observed, accompanied by a linearly increasing load up to $283 \mathrm{~N}$ (part II). During this part of the test, a straight crack is formed in the matrix (step 3 in figure 6), starting from the notch tip. In addition, an opening perpendicular to this crack is formed within the matrix (matrix-matrix debonding in step 3 of figure 6). With increasing load a stepwise growth of the crack within the matrix is observed (step 4). The crack is growing straight until it reaches fibre 1-2 (i.e. fibre 2 in layer 1, step 5). With further increasing load the matrix opens between fibre 1-1 and 1-2 (step 6). This opening or perpendicular cracking is observed at a position where independently grown regions during the CVI process, have met. Together with the previously observed opening the whole matrix mantle around fibre 1-2 fully debonds and bridges the crack. During this part of the test the crack is stable and only grows when the load is increased.

A massive load drop occurs after reaching the maximum load of $283 \mathrm{~N}$ (part III). Accompanied with the load drop the crack propagates almost completely through the sample (see figure 7). However, no complete failure is observed and still a load bearing capacity of $50 \mathrm{~N}$ remains. The crack has been deflected several times, mostly at matrix openings perpendicular to the original crack path. Some fibres are bridging the crack (fibre 1-2 and fibre 1-4), some fibres have failed. Compared to displacement step 6 a new crack plane has formed at fibre 1-2 and the formerly bridging fibre 1-1 has failed. With on-going displacement (part IV) several minor load variations are observed (steps 7-9). These are accompanied with no further crack propagation, but crack opening. After displacement step 10, the crack propagation continues. Due to the stepped crack path a strong wedging is observed, which is well visible at the matrix coating of fibre 1-2 and fibre 1-4. At step 11 the test is stopped before complete failure of the specimen.

The fracture toughness $K$ is determined according to ASTM E399 (equation A.3.1 and A3.2 in [22]). For the evaluation, the actual crack length must be known. In an inhomogeneous composite material such as $\mathrm{W}_{\mathrm{f}} / \mathrm{W}$ the determination of this length using only a surface observation is not possible [26]. Without detailed knowledge on the crack length over the whole sample thickness, the initial crack length, i.e. the length of the notch, is used for a conservative estimation of $K$. As a consequence of the rising load $K$ increases, although the crack length is kept constant. As the true crack length is clearly longer and even increases during the test, the true value of $K$ must be even higher. The determination of the fracture toughness is only valid for small deflections and is thus calculated only for values up to the maximum load. The values are shown in figure 8 . The fracture toughness of the matrix (crack initiation) is $5.9 \mathrm{MPa} \mathrm{m}^{0.5}$ and the maximum fracture toughness is $13.3 \mathrm{MPa} \mathrm{m}^{0.5}$. 


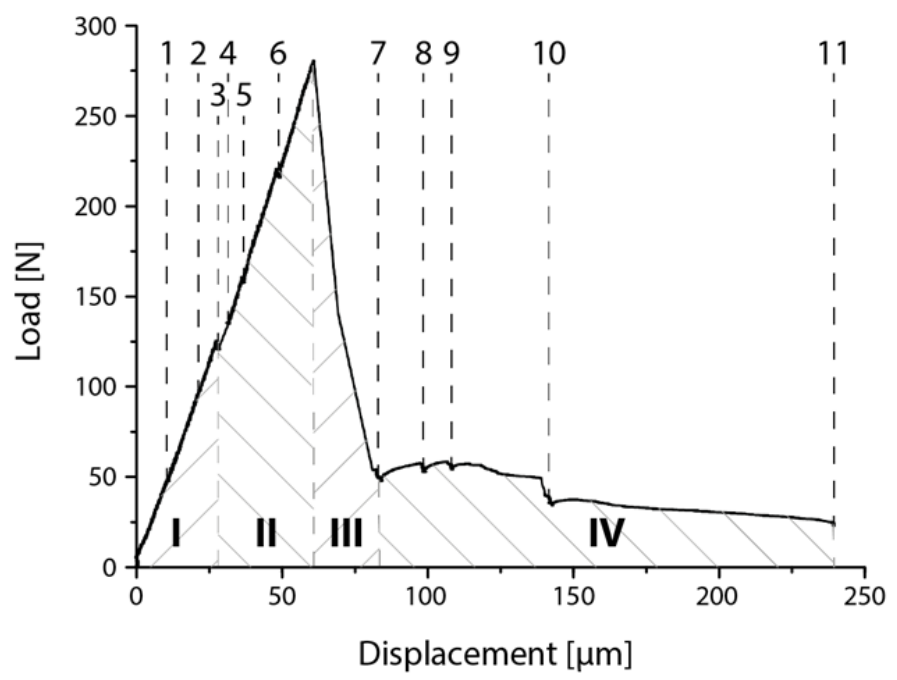

Figure 5: Force-displacement curve of the bending test on a multi-fibre $W_{f}^{\prime} W$ sample. The dashed lines indicate a displacement stop, accompanied by a detailed surface observation. Four different parts of the loading are identified with I to IV.

3

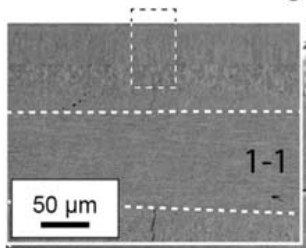

$250 \mu \mathrm{m}$

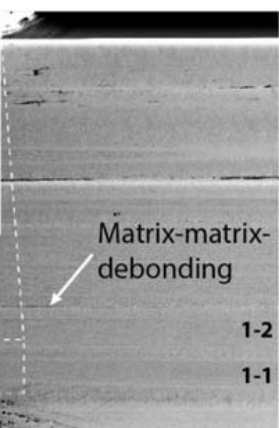

3

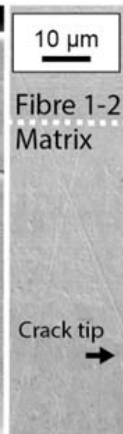

4

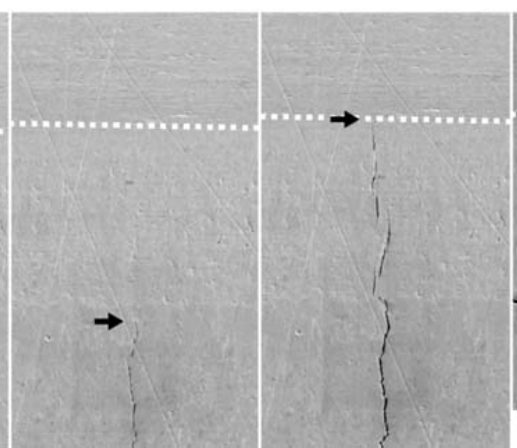

6

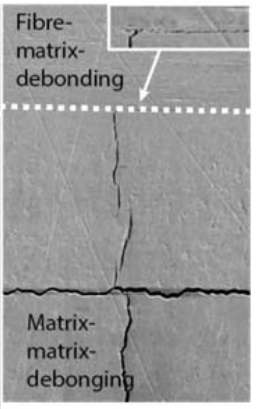

Figure 6: Surface observation after various displacement steps indicated by the number in the top row. The left picture shows the whole sample and in detail fibre 1-1 after crack initiation at displacement step 3. The straight crack in the matrix is indicated by matrix-matrix debonding. The four pictures to the right show the crack tip (marked with black arrows) at various displacement steps (location is indicated in the insert of the left picture by a dotted box). At displacement step 6, fibrematrix as well as matrix-matrix debonding is observed.

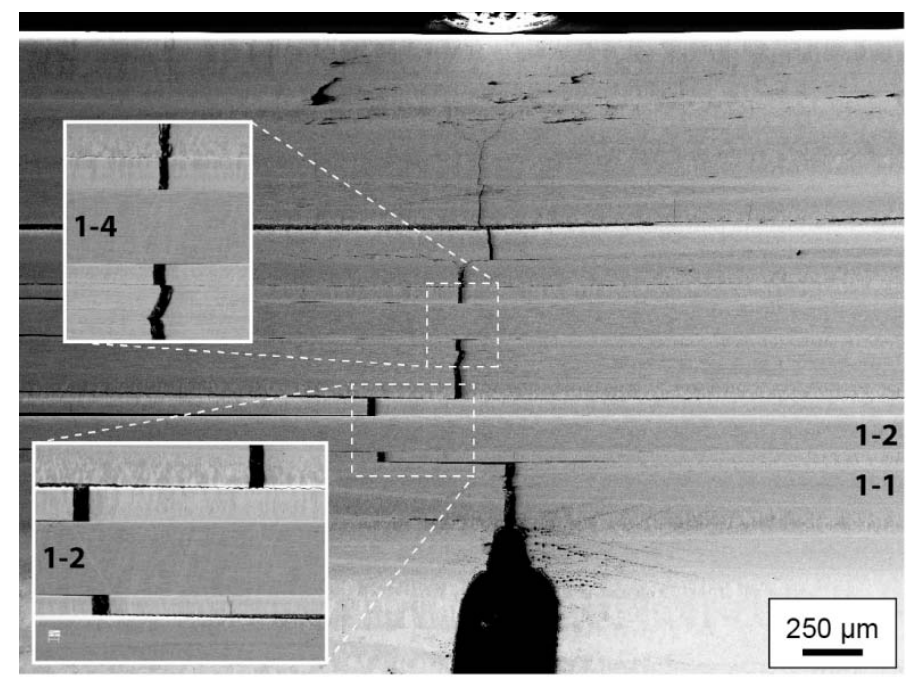

Figure 7: Surface observation of a multi-fibre sample after the massive load drop (displacement step 7). The sample can still bear load. Two inlays show bridging fibres in detail. 


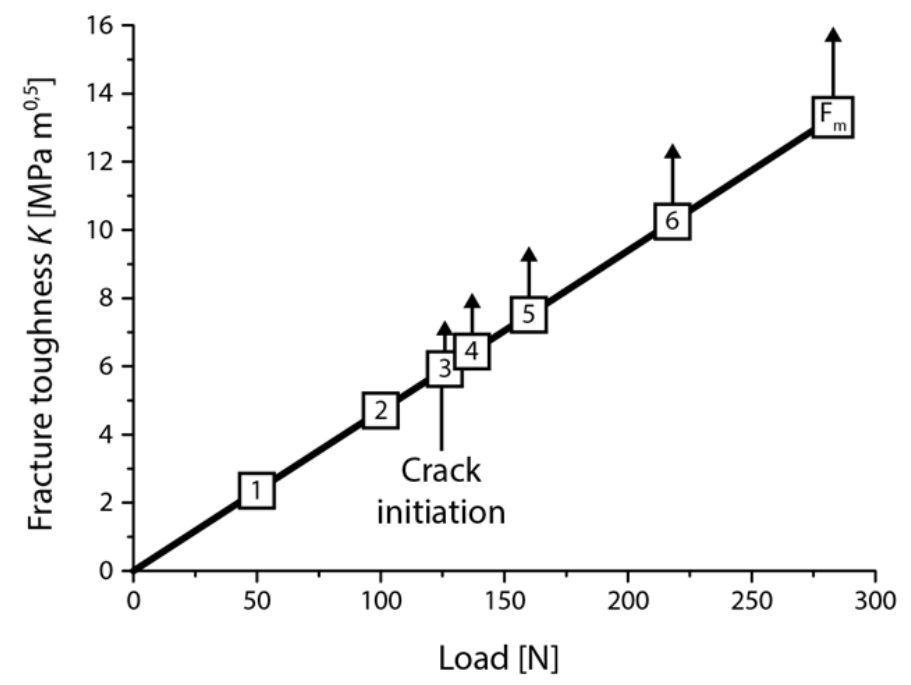

Figure 8: Fracture toughness $K$ calculated according to ASTM E399. $K$ is shown for each displacement step and for the maximum load. Since the initial notch length is used as crack length in the calculation, the true values of K are higher which is indicated by the arrows.

\section{Discussion}

At room temperature, tungsten typically fails in a mixture of cleavage fracture and grain boundary fracture [27]. Furthermore, below the ductile-to-brittle transition temperature, tungsten fractures in a brittle manner - these are well-known facts. The same fracture behaviour was reported for CVD tungsten [28]. The new composite $\mathrm{W}_{\mathrm{f}} / \mathrm{W}$, however, shows controlled, i.e stable, crack propagation and a rising load-bearing capacity. The stress intensity for the first visible crack propagation on the observed surface is in a typical range for undeformed (recrystallized, sintered) tungsten materials [29]. However, with increasing stable crack propagation, the load increases - leading to a pronounced increase in measured toughness. This behaviour is typical for a composite material with extrinsic toughening mechanisms [16] and the following mechanisms are active before reaching the maximum load:

- $\quad$ Bridging by intact fibres

- $\quad$ Bridging by intact matrix elements

- $\quad$ Energy dissipation by longitudinal matrix cracking

- $\quad$ Energy dissipation by fibre-matrix interface debonding

- $\quad$ Crack deflection and crack meandering at matrix-matrix and fibre-matrix interfaces

These toughening mechanisms have all been observed during the in-situ experiment. Only the first layer of fibres is visible on the specimen's surface and therefore only mechanisms acting in this layer are visible. A quantitative estimation of the contribution of each mechanism is not possible, as the surface observation does not provide any information about the interior of the sample. However, the observed strong toughening effect, e.g. the crack stopping within the matrix, indicates that these mechanisms are also active within the sample.

Clearly, a strong contribution to the toughening is provided by the bridging mechanism. This bridging is realized by single fibres as well as by freestanding matrix areas. In case of failure of multiple bridges, a massive load drop is the consequence. The crack bridging by intact fibres, as well as the energy dissipation by fibre-matrix interface debonding and crack deflection at these interfaces, have also been reported for single fibre composites [9, 10]. Interfaces within the matrix act as weak point and readily debond during the test. By doing so, whole matrix elements can act as crack-bridging elements. In addition, the crack is stopped and deflected at these interfaces. It was reported before, that such longitudinal cracks can contribute to the toughening [19]. 
This deboning within the matrix is a consequence of the prototype phase of the fabrication process and will be avoided by future process optimisation. However, the present study confirms that defects in the matrix due to fabrication do not necessarily lead to catastrophic failure of the composite as it is reported for brittle materials [11]. The toughening effect strongly increases the load-bearing capability even with crack propagation. After the crack initiation, the load can be further increased by a factor of two before a pronounced macroscopic effect occurs. The effect is estimated to an at least $120 \%$ increase in toughness compared to the not-reinforced bulk matrix material.

This study demonstrates for the first time the considerable extrinsic toughening effect originating from the energy dissipation caused by controlled interfacial debonding and sliding in a tungsten fibrereinforced tungsten composite. It suggests a promising application potential of the composite to plasma-facing armour for which thermal shock resistance is important. As armour of a plasma-facing component, the orientation of the reinforcing fibres needs to be aligned perpendicular to the main heat flow direction. If the composite undergoes overall interfacial debonding, the deterioration of the thermal conductivity in the vertical direction will be a concern. However, the reduction of the conductivity will not be so significant, because the matrix is connected through the volume while debonding occurs at the cylindrical interface of the embedded fibres. Therefore the thermal conductivity of the matrix - which is the dominating heat transport mechanism - is only marginally deteriorated.

\section{Conclusion and outlook}

In this work, the first mechanical experiment on tungsten fibre-reinforced tungsten composites containing multiple fibres is presented. An active extrinsic toughening effect is demonstrated in a qualitative and quantitative in-situ analysis. Several mechanisms are observed which lead to a controlled, i.e. stable, crack propagation and a rising load-bearing capacity. As a consequence, the toughness of the composite material is strongly increased leading to damage tolerance. The composite can therefore withstand local overloads or fabrication flaws.

A detailed examination of the fracture surface together with an analytical description of the experiment will be presented in a succeeding paper. In the near future optimised samples with low porosity and improved interfaces will be tested.

\section{Acknowledgements}

The authors want to acknowledge support by Osram GmbH, Schwabmünchen, Germany for providing the tungsten wire, and Archer Technicoat Ltd, High Wycombe, UK for the CVD production. The activities leading to these results have partially received funding from the European Atomic Energy Community’s Seventh Framework Programme (FP7/2007-2011) under Grant

Agreement 224752 and from the European Fusion Development Agreement. The views and opinions expressed herein do not necessarily reflect those of the European Commission.

\section{References}

[1] N. Baluc. Final report on the EFDA task tw1-ttma-002 deliverable 5. Technical report, Centre de Recherches en Physique de Plasmas, 2002.

[2] R. Lässer, N. Baluc, J.-L. Boutard, E. Diegele, S. Dudarev, M. Gasparotto, A. Möslang, R. Pippan, B. Riccardi, and B. van der Schaaf. Structural materials for DEMO: The EU development, strategy, testing and modelling. Fusion Engineering and Design, 82:511-520, 2007.

[3] J.-H. You and I. Komarova. Probabilistic failure analysis of a water-cooled tungsten divertor: Impact of embrittlement. Journal of Nuclear Materials, 375:283-289, 2008.

[4] S.Wurster et al. Recent progress in R\&D on tungsten alloys for divertor structural and plasma facing materials. Journal of Nuclear Materials, 2013, in press.

[5] M. Rieth et al. Recent progress in research on tungsten materials for nuclear fusion application in Europe. Journal of Nuclear Materials, 432:482-500, 2013. 
[6] J. Du, T. Höschen, M. Rasinski, S. Wurster, W. Grosinger, and J-H. You. Feasibility study of a tungsten wire reinforced tungsten matrix composite with $\mathrm{ZrO}_{\mathrm{x}}$ interfacial coatings. Composites Science and Technology, 70:1483-1489, 2010.

[7] J. Du, T. Höschen, M. Rasinski, and J.-H. You. Interfacial fracture behavior of tungsten wire/tungsten matrix composites with copper-coated interfaces. Materials Science and Engineering: A, 527:16231629, 2010.

[8] J. Riesch. Entwicklung und Charakterisierung eines wolframfaserverstärkten WolframVerbundwerkstoffs. Ph.D. thesis, Technische Universität München, 2012

[9] J. Riesch, J.-Y. Buffiere, T. Höschen, M. di Michiel, M. Scheel, Ch. Linsmeier, J.-H. You. In-situ synchrotron tomography estimation of toughening effect by semi-ductile fibre reinforcement in a tungsten fibre-reinforced tungsten composite system. Acta Materialia, accepted

[10] J. Riesch, J.-Y. Buffière, T. Höschen, M. Scheel, J.-H. You. Crack bridging in as-produced and embrittled tungsten single fibre reinforced tungsten composites shown by a novel in-situ high energy synchrotron tomography bending test. Acta Materialia, ready to submit

[11] A.G. Evans. Overview no. 125: Design and life prediction issues for high-temperature engineering ceramics and their composites. Acta Materialia, 45:23-40, 1997.

[12] M.E. Launey and R.O. Ritchie. On the fracture toughness of advanced materials. Advanced Materials, 21:2103-2110, 2009.

[13] R.O. Ritchie. Mechanisms of fatigue crack propagation in metals, ceramics and composites: Role of crack tip shielding. Materials Science and Engineering: A, 103:15-28, 1988.

[14] K.K. Chawla. Ceramic matrix composites. Chapman \& Hall, 1993.

[15] R.H. Jones and C.H. Henager, Jr. Subcritical crack growth processes in SiC/SiC ceramic matrix composites. Journal of the European Ceramic Society, 25:1717-1722, 2005.

[16] A.G. Evans. Perspective on the development of high-toughness ceramics. Journal of the American Ceramic Society, 73:187-206, 1990.

[17] John B. Wachtman. Mechanical Properties of Ceramics. John Wiley \& Sons, Inc., 1996.

[18] A.G. Evans and F.W. Zok. Review - the physics and mechanics of fibre-reinforced brittle matrix composites. Journal of Material Science, 29:3857-3896, 1994.

[19] J.-K. Kim and Y.-W. Mai. Engineered interfaces in fiber reinforced composites. Elsevier Science Ltd., 1998.

[20] S.R. Pemberton, E.K. Oberg, J. Dean, D. Tsarouchas, A.E. Markaki, L. Marston, and T.W. Clyne. The fracture energy of metal fibre reinforced ceramic composites (mfcs). Composites Science and Technology, 71:266-275, 2011.

[21] J. Riesch, T. Höschen, A. Galatanu, J.-H. You. Tungsten-fibre reinforced tungsten composites: A novel concept for improving the toughness of tungsten. Proceedings of the 18th International Conference on Composite Materials (ICCM18), 2011

[22] ASTM International. Standard Test Method for Plane-Strain Fracture Toughness of Metallic Materials. ASTM E 399 - 90 (Reapproved 1997)

[23] A. Manhard, G. Matern and M. Balden. A Step-by-step Analysis of the Polishing Process for Tungsten Specimens. Praktische Metallographie / Practical Metallography, 50, 5-16 (2013)..

[24] B. Tabernig and R. Pippan. Determination of the length dependence of the threshold for fatigue crack propagation. Engineering Fracture Mechanics, 69:899-907, 2002.

[25] S. Wurster, B. Gludovatz, A. Hoffmann and R. Pippan. Fracture behaviour of tungsten-vanadium and tungsten-tantalum alloys and composites. Journal of Nuclear Materials, 413:166-176, 2011.

[26] D.B. Marshall, B.N. Cox, and A.G. Evans. The mechanics of matrix cracking in brittlematrix fiber composites. Acta Metallurgica, 33:2013-2021, 1985.

[27] C. Gandhi and M.F. Ashby. Fracture-mechanism maps for materials which cleave: F.C.C., B.B.C., and H.C.P. metals and ceramics. Acta Metallurgica, 27:1565-1602, 1979.

[28] J.D. Murphy, A. Giannattasio, Z. Yao, C.J.D. Hetherington, P.D. Nellist, and S.G. Roberts. The mechanical properties of tungsten grown by chemical vapour deposition. Journal of Nuclear Materials, 386-388:583-586, 2009.

[29] M. Faleschini, H. Kreuzer, D. Kiener, R. Pippan. Fracture toughness investigations of tungsten alloys and SPD tungsten. Journal of Nuclear Materials, 367-379:800-805, 2009. 